\title{
REALPOLITIK, ECONOMÍA Y PROPAGANDA EN TORNO AL PARLAMENTARISMO BRITÁNICO: EL TESTAMENTO POLÍTICO DEL ALMIRANTE BYNG (1780)
}

\author{
REALPOLITIK, ECONOMY AND PROPAGANDA ON THE \\ BRITISH PARLIAMENTARISM: THE POLITICAL \\ TESTAMENT OF THE ADMIRAL BYNG (1780)
}

\author{
Jesús Astigarraga \\ Javier Usoz \\ Universidad de Zaragoza
}

\begin{abstract}
SUMARIO: I. INTRODUCCIÓN: UN TEXTO SOBRE LA REALPOLITIK BRITÁNICA.- II. EL TESTAMENT POLITIQUE EN EL ÁMBITO FRANCÉS Y SU TRADUCCIÓN ESPAÑOLA.- III. LOS "VICIOS INVETERADOS" DEL SISTEMA POLÍTICO BRITÁNICO.- IV. EN DEFENSA DEL LIBRE COMERCIO.- V. A MODO DE CONCLUSIONES.
\end{abstract}

Resumen: El testamento politico del almirante Byng (1780) es la traducción de una obra anónima francesa publicada en 1759, al calor de la Guerra de los Siete Años. Constituye un caso significativo de la circulación internacional de las ideas en la Europa del siglo XVIII. Si sus aspectos formales hablan de nuevas formas literarias para tratar asuntos políticos y económicos, sus contenidos aún ofrecen más interés. Tanto en el objeto como en el método, la obra es un ejemplo de propaganda y de realpolitik ilustrada. Así, desde la perspectiva francesa en el mencionado conflicto bélico, se aborda críticamente la problemática del sistema parlamentario británico y se defiende un comercio libre no supeditado a los privilegios de las grandes compañias comerciales. Tales contenidos políticos y económicos, junto a la declaración de la guerra librada entre británicos y españoles entre 1779 y 1783, estuvieron tras el interés de las autoridades españolas que encomendaron la traducción y la difusión de la obra en cuestión.

\begin{abstract}
El testamento politico del almirante Byng (1780) is the translation of an anonymous French work published in 1759, in the heat of the Seven Years' War. The translation is a significant case of the international circulation of ideas in the eighteenth-century Europe. If the book's formal aspects are an example of new literary tools to deal with political and economic issues, its content is even more relevant. From both perspectives, the work is an example of enlightened propaganda and realpolitik. Defending the French approach to the aforementioned war conflict, the book addresses critically the problems derived from the British parliamentary system and take a stance for free trade not subordinated to the privileges of large commercial companies. Such political and economic contents, together with the declaration of the British-Spanish war between 1779 and 1783, were at the interest of the Spanish authorities who commissioned the translation of the book and its later dissemination.
\end{abstract}


Palabras clave: Circulación internacional de las ideas, Ilustración española, opinión pública, parlamentarismo británico, libertad de comercio.

Key Words: International circulation of ideas; Spanish Enlightenment; public opinion; British parliamentarism; free trade.

\section{I.- INTRODUCCIÓN: UN TEXTO SOBRE LA REALPOLITIK BRITÁNICA}

En 1969, hace ahora medio siglo, José Antonio Maravall, en uno de sus espléndidos estudios sobre el siglo XVIII español, aludía de manera sucinta a un texto hasta esa fecha desconocido del que destacaba su profundo contenido político, que versaba sobre el peculiar sistema constitucional y parlamentario británico $^{1}$. Con el título de Testamento político del almirante Bing ${ }^{2}$, se trataba de una traducción de la obra francesa de 1759 titulada Testament politique de l'amiral Byng, la cual, a su vez, se anunciaba en el subtítulo como una traducción de un texto inglés, publicado supuestamente en Portsmouth y escrito, sabemos que ficticiamente, por John Byng, el auténtico oficial de la Armada británica ejecutado por su comportamiento en la defensa de Menorca frente al enemigo francés, en 1756, al poco de iniciarse las hostilidades de la Guerra de los Siete Años (1756-1763) ${ }^{3}$.

Como se verá en este estudio, es destacable que Byng fuera doblemente utilizado en términos propagandísticos. Por una parte, su pública ejecución fue el aviso a navegantes que hicieron las autoridades británicas, respecto a que no iban a consentir la menor tibieza en el desarrollo de la guerra, al mismo tiempo que se exculpaban de sus responsabilidades en la pérdida de Menorca ante los franceses por la mala gestión de los recursos que el propio Byng había manifestado antes de entrar en combate. De ahí la excepcionalidad del castigo, particularmente en cuanto que el almirante no obtuvo del 'Gabinete' gobernante en Gran Bretaña la condonación de la pena de muerte que se solicitaba en la sentencia y de la que se haría eco después el Parlamento. En segundo término, en sentido inverso, el dramático final de Byng y su propia personalidad fueron utilizados como arma arrojadiza contra la decisión de declarar la guerra a Francia. En este caso, por razones lógicas, no se manifiestan claramente las manos que manejan los hilos, pero es más que probable la alianza implícita entre

* Los autores de este estudio quieren dedicarlo a la memoria del Profesor Joaquín Varela Suanzes-Carpegna.

Este trabajo se integra en el Proyecto de Investigación HAR2016-77344-R y en el Grupo de Investigación del Gobierno de Aragón H26_17R.

1 José Antonio Maravall, "Las tendencias de reforma politica en el siglo XVIII español", en Estudios de la historia del pensamiento español (siglo XVIII), Mondadori, Madrid, 1991, p. 69.

2 Testamento politico del almirante Bing en el que se manifiestan las máximas del partido realista para sojuzgar al pueblo inglés y quitarle la libertad que se ha adquirido; y asi mismo la senda que éste debe seguir para conservarla. Traducido del francés por Don Antonio Rato, Oficial primero de la Tesorería del Ejército y Reino de Valencia, José y Tomás de Orga, Valencia, 1780.

3 Testament politique de l'amiral Byng, traduit de l'anglois, s. e., Portsmouth [París], 1759. 
los intereses de Francia, la potencia agredida sorpresivamente en el inicio de la contienda, y los intereses de los sectores británicos contrarios a las politicas que sostenian la guerra recién declarada, más cercanos, como se verá, a la concepción socioeconómica "tory" que a la visión gobernante "whig". Finalmente, cabe hacer una mención a los familiares del propio John Byng, quienes todavía en la actualidad se hallan en vias de reivindicar el honor injustamente mancillado de su ancestro ${ }^{4}$. Quizás los deudos coetáneos de este hubieron de consentir el uso espurio de su apellido en la lucha propagandística que se libró, bien porque no estuvieron en condiciones de impedirlo, o bien porque no tuvieron otra oportunidad mejor de defender la memoria del almirante.

Volviendo a las palabras de Maravall, el texto consistía esencialmente, en expresión del propio original, en un "alegato contra la ambición del partido del Rey en Inglaterra", con el fin de llamar "la atención del Parlamento contra las maquinaciones tiránicas del partido realista y señalando los principios de la libertad del pueblo inglés que se han basado de antiguo en abatir el poder real". Todo ello, proseguía Maravall, había transcurrido a través de dramáticos avatares que, parafraseando el texto, "han conducido a la Nación británica a este punto de libertad y de ser partícipe en la legislación, en que consisten su felicidad y grandeza"; un "punto de libertad" que, como el profesor apuntaba con agudeza, no tenía paragón con el de la España de 1780, la fecha en que fue realizada la traducción española del texto.

Marginada en el olvido desde entonces, como de hecho también lo ha venido siendo el propio original en lengua francesa, apenas considerado hasta la fecha por la historiografia, esta enigmática y enrevesada traducción merece sin duda ser recuperada con el fin de seguir enriqueciendo lo que ya se conoce acerca de las fuentes intelectuales del siglo XVIII español.

A modo de mapa general, cabría sostener que, considerando el original y la traducción, la vertiente eminentemente propagandística de su contenido tendría varios niveles de comprensión, en función del público al que se dirigió y de la época en que fuera leído. Los dos primeros niveles se refieren a la mitad del siglo XVIII, en plena Guerra de los Siete Años, e incluyen al público británico, por un lado, y al francés, por otro, lo cual, a su vez, teniendo presente que el idioma francés era la lengua franca de Occidente, incluiria a las élites de otras latitudes europeas también implicadas en el conflicto bélico, en un bando y otro, particularmente el público de los territorios alemanes más ligados a la contienda, tanto por el pacto existente entre Inglaterra y Prusia, como por su relación con la Casa de Hannover, reinante en Inglaterra.

Por lo que respecta al público británico, no hay duda de que este pudo captar mejor que ningún otro la acerada critica de realpolitik contenida en el Testament, escrito que no se entiende sin referirlo al funcionamiento concreto y efectivo del constitucionalismo británico emergido de la Revolución de $1688^{5}$.

\footnotetext{
4 Vid., https://www.theguardian.com/uk/2007/mar/15/military.immigrationpolicy.

${ }^{5}$ Para los objetivos del presente trabajo, nos servimos de la madura interpretación de Joaquín Varela Suanzes-Carpegna, "El constitucionalismo británico entre dos constituciones: 1688-1789", Fundamentos. Cuadernos monográficos de Teoría del Estado, Derecho público e Historia constitucional, $\mathrm{n}^{\circ}$ 2, 2000, pp. 8-59, y, adicionalmente, del mismo autor, "El debate constitucional británico en la primera mitad del siglo XVIII (Bolingbroke versus Walpole)", Revista de Estudios Políticos, $\mathrm{n}^{\circ}$ 107, 2000, pp. 9-32.
} 
Dicho sistema, de por sí complejo y dotado de una ambigüedad que tiene que ver con su naturaleza histórica y con sus fuentes, tanto escritas como cifradas en la costumbre, había derivado hacia una clara divergencia entre la Constitución "formal" y la "material". La primera, asociada a las ideas de Locke y refrendada por el pensamiento de figuras políticas del sector "tory" como Bolingbroke o Blackstone, estaba basada en las normas jurídicas, procedentes del Parlamento y de las decisiones judiciales, así como en una clara división de poderes y de funciones, correspondientes al Rey, a la Cámara de los Comunes y a la de los Lores. Por otra parte, la que se conoce como Constitución "material", más apreciada y promovida por los políticos "wighs", como Walpole, Burke o Fox, incorpora de modo decisivo a lo anterior todo el conjunto de "convenciones" o prácticas y reglas politicas que, a través de lo que el profesor Varela considera como una "revolución invisible", produjeron de hecho una progresiva "parlamentarización" del sistema, que pasaría de "constitucional" a "parlamentario". Esta evolución del sistema dio lugar a la hegemonía del "Gabinete", presidido por el Primer Ministro, de modo que las decisiones de este quedaban bajo el control exclusivo de la Cámara de los Comunes, cuyos miembros estaban muy influidos por los fondos, prebendas y privilegios que recibían de la Monarquía, dominada, a su vez, por el Gabinete, por la ausencia y la inacción del monarca, especialmente, desde 1714 hasta 1760. Así, Jorge I (1714-1727) y Jorge II (1727-1760) prácticamente desconocían el idioma inglés y residian habitualmente en Alemania, de modo que dejaron sus funciones constitucionales en manos del mencionado Gabinete. Solo el advenimiento al trono de Jorge III (1760-1789) supuso un cambio en el proceder descrito anteriormente, con su intento, por ejemplo, de tomar un mayor control personal de los nombramientos para cargos públicos, si bien las decisiones del Gabinete siguieron mateniendo su protagonismo.

De manera que el escrito del que tratamos fue un sofisticado instrumento propagandístico que sirvió a la causa del partido "tory", el cual, por razones que se remontan a su actitud favorable a la Corona durante la Revolución de 1688, fue incapaz de acceder al poder durante casi todo el siglo XVIII. Hay que tener presente que la guerra contra Francia fue apoyada por el partido "whig", puritano, partidario de la hegemonía del Parlamento y defensor de la pujante burguesia comercial e industrial, conforme a una visión económica "moderna" protagonizada por el afán de lucro y la extensión del lujo. Robert Walpole, primer ministro de 1721 a 1742, fue el gran exponente político de esta visión, si bien en el periodo que nos ocupa y respecto a la Guerra de los Siete Años, el protagonismo fue del también "whig" William Pitt "El Viejo", primer ministro de 1757 a 1761 y de 1766 a 1768 . Frente a la concepción anterior se encuentran las reservas del sector "tory", más netamente anglicano, defensor del papel de la Corona, en una posición difícil, pues en la práctica no fue su aliada, así como partidario, según lo refrenda la obra de que estamos tratando, de los valores e intereses de la pequeña aristocracia rural, de los artesanos y de los comerciantes tradicionales. Su figura esencial en la primera mitad del siglo fue Henry SaintJohn, primer Vizconde de Bolingbroke.

En este marco, el contenido del Testament indica que hubo una coincidencia entre las pretensiones de Francia y las del sector 'tory' más vinculado a la Inglaterra tradicional, en aras de mantener la situación geopolítica internacional y colonial pactada a comienzos del siglo XVIII, tras la Guerra de Sucesión 
española, con el fin de evitar los costes de una guerra que se proponía beneficiar a los monopolios de las grandes compañias comerciales británicas. Por razones obvias, en un contexto de guerra declarada, dicha coincidencia no podía ser expresada claramente por ningún agente relevante de la política británica.

Por lo tanto, ciertamente, la traducción al castellano del Testament se dirigió al público español en 1780 con unos objetivos propagandísticos forzosamente diferentes a los que estaban presentes en 1759. En el caso español no hay duda de que la obra se adscribe más rotundamente a los contornos plurales y amplios que adquirió en el siglo XVIII, en particular durante su segunda mitad, el intenso proceso de emergencia de la Economía Política y, aunque ello haya sido injustamente olvidado, a la ubicua función que esta ciencia cumplió como precursora del debate constitucional que eclosionará en las dos últimas décadas del siglo XVIII español. La traducción reflejaba el interés creciente de los traductores de la Ilustración española por apropiarse de nuevos estilos narrativos, que, como en el caso que nos ocupa, trascienden el formato del tratado o del ensayo al uso. Con fines propagandísticos y persuasivos, a partir de hechos reales, se crea una autoría de ficción, como si se tratara de las últimas palabras de un condenado a muerte, aprovechando así un trasfondo dramático real que infunde un tono de autenticidad al contenido de la obra y llega a un público más amplio. Su finalidad desbordaba el propósito del mero entretenimiento. El sentido de utilidad y de intencionalidad politica, rayando en algunos pasajes en el adoctrinamiento, estaba presente en todo el texto, que encubría un panfleto propagandístico destinado a apuntalar entre sus lectores dos ideas centrales que se repetían incesantemente en él: una crítica minuciosa del sistema político y económico británico, así como una diatriba radical en favor del libre comercio, la cual, no en vano, estaba muy ligada a la reciente política de una moderada liberalización del mercado colonial español, de modo que pudo ser un motivo adicional de su traducción y de su publicación en España. El libro se podía así adscribir a un género presente, si bien de forma minoritaria, en la Ilustración española, consistente en la dramatización literaria de un contenido político-económico ${ }^{6}$.

\section{II.- EL TESTAMENT POLITIQUE EN EL ÁMBITO FRANCÉS Y SU TRADUCCIÓN ESPAÑOLA}

Si en términos formales y de estilo literario el Testament politique era singular, en cuanto a su contenido no sucedia lo mismo. El libro era más bien otra muestra de la intensa circulación de ideas, personas y libros entre Gran Bretaña y Francia que caracterizó la fértil década de los años cincuenta del siglo XVIII. Ese flujo encendió en Francia una polémica sobre el sistema británico, que enfrentó a anglófilos y anglófobos. Su clímax se alcanzó a raíz del inicio en 1756

${ }^{6}$ Otro, ejemplo adscrito a un género similar, procede de otra traducción francesa: el Chinki del abate Coyer; vid. Jesús Astigarraga, "Literatura económica de combate. La traducción española del Chinki de Coyer", en J. A. Pardos et. al. (eds.), Historia en Fragmentos. Estudios en homenaje a Pablo Fernández Albaladejo, Universidad Autónoma de Madrid, Madrid, 2017, pp. 691-700. 
de la Guerra de los Siete Años que enfrentó inicialmente a esas dos naciones ${ }^{7}$. En el caso concreto del Testament politique, el flujo intelectual entre el Canal de la Mancha estaba instigado por el popular "affaire" de John Byng —o Bing-. Almirante de la armada real, Byng (1704-1757) habia sido hecho responsable, por parte de las autoridades británicas, de la derrota humillante que la armada francesa había infligido a la británica en Menorca, en mayo de 1756, durante los primeros meses de la guerra, debida en buena medida a las condiciones muy desiguales en que hubo de desenvolverse la armada por él dirigida. La derrota en el puerto de Mahón supuso la pérdida de esa isla, bajo dominio británico desde la Guerra de Sucesión (1708) y, desde ese momento, un enclave británico estratégico en el Mediterráneo. La suerte de Byng, un reputado marino hasta esa fecha, fue marcada por este episodio bélico. Una vez perdida la isla, se dirigió a Gibraltar, para reparar las naves dañadas, con el propósito de retornar después al archipiélago para recuperar Menorca; sin embargo, fue relevado antes de que todo ello sucediera. A su regreso a Gran Bretaña le esperaba una corte marcial que le culpabilizó de la derrota y le sentenció a muerte. A pesar de las numerosas peticiones de clemencia, fue ejecutado en el puerto de Portsmouth el 14 de marzo de $1757^{8}$. La severidad de este castigo alentó la sospecha de que era una decisión ejemplarizante adoptada en las primeras escaramuzas de la guerra, destinada a distraer al público británico de la humillación sufrida por Gran Bretaña, debida a la incompetencia de las autoridades politicas responsables de la contienda, especialmente el primer ministro, el duque de Newcastle, y el primer Lord del Almirantazgo, Anson. Todo ello instigó una reacción favorable a Byng, canalizada durante los meses que rodearon su juicio y su ejecución a través de numerosos libelos y panfletos literarios y políticos.

Los ecos del "affaire" Byng llegaron de forma inmediata a Francia. En este país ganó una notoriedad notable en la República de las letras debido a que Voltaire intercedió personalmente a favor del reo ${ }^{9}$. El filósofo remitió una carta en la que adjuntaba otra misiva de su amigo y protector Louis François de Vignerot du Plesis, duque de Richelieu, vencedor de la batalla de Menorca, en la que este le expresaba su admiración al almirante inglés. Sin embargo, la carta, interceptada y hecha pública, fue interpretada como una traición y no mejoró la suerte de su destinatario. Consumada la ejecución, Voltaire evocaría satíricamente a Byng en su popular novela Candide (1759), al hacer que el protagonista asistiera a la ejecución de un oficial: "Dans ce Pays-ci, il est bon de tuer de temps en temps un Amiral pour encourager les autres"10.

7 Una visión general en Edmond Dziembowski, Un nouveau patriotisme français, 1750-1770, Voltaire Foundation, Oxford, 1998, y Joséphine Grieder, Anglomania in France 1740-1789, Droz, Ginebra, 1985.

8 Chris Ware, Admiral Byng: his rise and execution, Pen and Sword Maritime, Barnsley, 2009, pp. 151-153. La isla de Menorca estuvo en manos francesas hasta la paz de Versalles (1763) cuando volvió a dominio británico; en 1783 regresó al español.

9 André-Michel Rousseau, "L'Angleterre et Voltaire (1718-1789)", en Studies in Voltaire and the Eighteenth Century (vol. 145), Voltaire Foundation y The Taylor Institution, Oxford, 1976, pp. 219231, y Amstrong Starkey, 'The Seven Years' War. Global Views, Brill, Leiden-Boston, 2012, pp. 23-27.

10 Voltaire, F.-M. Arouet, Candide, ou l'optimisme (1759), Genève, 1761, p. 170. 
Dos años antes, a lo largo de 1757, durante los meses que antecedieron y siguieron a la ejecución, Voltaire abordó el caso de Byng en sus cartas dirigidas al propio Richelieu, en las que le agradecía su implicación y le informaba de la evolución del asunto hasta su dramático final, así como en las que dirigió a sus amistades Thieriot y la condesa de Lutzelbourg ${ }^{11}$. En dicha correspondencia Voltaire comparaba el caso de Byng con el de Miguel Servet, manifestaba su poco aprecio por el insensible espíritu inglés y, además, se refería al Testament como un libro cuyos "cálculos y todos los hechos son falsos" y cuya autoría, frente a lo que afirmaba que se venía diciendo, no era debida a Richelieu, tal y como lo evidenciaba, insistía Voltaire, que el autor "olvida hablar del Rey de Prusia, de María Teresa y del Duque de Hannover"12.

Efectivamente, todo lo anterior estaba movido por un cosmopolitismo humanitario que denunciaba el belicismo y la barbarie británica. Desde luego, la simpatía por Byng floreció en la ola de la victoria francesa en Menorca, pero también como una expresión más de la campaña que, con el telón de fondo de la guerra, trataba de azuzar en Francia el sentimiento anglófobo. De hecho, antes de finalizar la década de los años cincuenta, vieron la luz diversas traducciones, narraciones y poemas en defensa de Byng, de la mano de autores de la influencia de Edme-Jacques Genet ${ }^{13}$. En ese contexto preciso tuvo lugar la aparición del Testament politique.

No existe mucha información sobre los detalles concretos de su elaboración y su publicación. Si el pie de imprenta en Portsmouth era sin duda figurado evocaba el lugar donde Byng había sido ejecutado-, el texto no solo fue publicado anónimo sino que en la actualidad se desconoce a su autor. La argucia literaria y editorial estaba diseñada para hacer pensar al lector que el propio almirante Byng era el autor. En efecto, el libro era una narración en primera persona del propio almirante británico, su testamento político, profesado "sin violencia ni ánimo de venganza", cuando se habian dictado los graves cargos contra su persona de "falta al Rey, al Estado y a la patria"14. La narración de Byng tenía por tanto como telón de fondo el escenario de esa guerra recién iniciada, incluida la toma de Menorca, la prueba del cargo acusatorio contra él. A juicio del narrador, la derrota se debió únicamente a la escasez de navíos, la debilidad del armamento y la falta de apoyo logístico desde Gibraltar, de tal forma que el reo Byng optaba por consumir los últimos momentos de su vida en

11 Voltaire, F.-M. Arouet, Oeuvres complètes de Voltaire (vol. LXVI). Correspondance Général (vol. V), Badouin Frères, París, 1828, pp. 19-20, 30, 36, 40, 52-53.

12 Voltaire, Oeuvres completes, op. cit., p. 52.

13 Entre los textos principales figuran: Charles premier, roi d'Angleterre, condamné à mort par la nation angloise, et Bing, amiral anglois, fusillé par ordre de la même nation. Entretiens de leurs ombres aux Champs Elisées, J. Neaulne, Ámsterdam, 1757; fue conocido popularmente como Entretiens aux Champs Élisées y fue reeditado en 1785; Bing au peuple anglois, [París], 1760; se trató de un poema indebidamente atribuido a Voltaire; y, por último, el libro que se atribuye a Edme-Jacques Genet (Mémoire pour les ministres d'Angleterre, contre l'amiral Byng et contre l'auteur du Peuple instruit. Ouvrage traduit de l'anglois, s. e., s. 1., 1757), periodista al servicio del poderoso Secretario de Estado, Choiseul. También salió en defensa de Byng, Samuel Johnson, cuyo célebre aforismo "el patriotismo es el último refugio de los canallas" encontraba una magnifica prueba refutatoria en el affaire Byng (Escritos politicos (ed. Donald J. Green), Katz, Buenos Aires, 2009, pp. 255 y ss.).

14 Testamento politico, op. cit., p. 4. 
defenderse, justificar su conducta y apuntar con el dedo acusatorio a la Corte de Londres, aun a sabiendas de que el resultado sumario de su proceso - simple resultado del "capricho más injusto" 15 - se hallaba decidido de antemano. Aunque "el siglo es demasiado ilustrado" para dictar la sentencia sin pruebas definitivas del reo como traidor o cobarde, Byng relataba su narración cuando, ya dictada la sentencia de muerte, los jueces imploraban con pocas esperanzas la clemencia del Rey.

En cualquier caso, la fecha de publicación del libro y las informaciones de las revistas de la época desdicen de inmediato la posible atribución del mismo a Byng. En el Journal encyclopédique se sugería que el autor pudo ser el mismo que había publicado en 1757 otra obra sobre el propio Byng - los mencionados Entretiens aux Champs Élisées (vid. nota 13)—, que él habia recensionado un año después; sin embargo, naturalmente el firmante de esta reseña no identificaba al autor de ambas obras ${ }^{16}$. Otras fuentes atribuyen el texto a Ange Goudar, si bien sin aportar pruebas concluyentes ${ }^{17}$. Este polifacético periodista y literato no era desconocido en España, pues en 1772 el miembro de la Hacienda Domingo de Marcoleta había publicado una traducción de su principal obra económica ${ }^{18}$.

A diferencia del autor del texto, sí conocemos al traductor español, Antonio Rato, oficial primero de la Tesorería del Ejército y Reino de Valencia. No obstante, carecemos de noticias acerca de su vida y de sus actividades literarias, más allá de que con toda probabilidad el Testamento político fue el único texto publicado por él19. La traducción vio la luz en Valencia, donde cumplía sus obligaciones profesionales. Realizada, como se ha señalado, por encargo, su intencionalidad parecía clara. Fue publicada en un extenso formato de casi tres centenares de páginas, al inicio del nuevo conflicto bélico anglo-español de 1779-1783, originado por el apoyo que España prestó a las trece colonias británicas en la Guerra de Independencia de los Estados Unidos. España vio en la guerra una oportunidad para debilitar el poder británico y acaso recuperar las pérdidas cosechadas en la Guerra de los Siete Años, incluidos los enclaves de Gibraltar y Menorca -de hecho, España recuperaría la isla de Menorca en el Tratado de París de 1783-. De esta manera, aunque el Testament Politique cumpliera dos décadas cuando vio la luz la traducción española, el nuevo escenario bélico abierto en 1779 constituía un marco perfecto para hacer circular el relato de Byng, aprovechando su interpretación anglófoba. De hecho, la prensa española volvió a recordar en esos años su derrota en Menorca como un ilustrativo episodio de la debilidad de la armada británica ${ }^{20}$.

La traducción era íntegra, sin añadidos ni notas propias. Ello impedia la actualización de un texto que poseía más de dos décadas y, en suma, en su fecha

15 Testamento politico, op. cit., p. 272.

16 Journal encyclopédique, abril 1759, pp. 100-109. Debemos estas informaciones a la amabilidad y la erudición de la investigadora francesa Ch. Théré.

17 Jean-Claude Hauc, Ange Goudar. Un aventurier des Lumières, Honoré Champion, París, 2004 , p. 82 .

18 Se alude a Les intérêts de la France mal entendus, Ámsterdam [Avignon], 1756, 3 vol.

19 Esto se desprende de la bibliografía de Francisco Aguilar Piñal, Bibliografía de autores españoles del siglo XVIII, CSIC, Madrid, 1981-2001, vol. VII, p. 46.

20 Vid., por ejemplo, el Mercurio Histórico y Politico, agosto 1778, p. 379. 
de publicación resultaba anacrónico: ni siquiera se mencionaba la pérdida de las colonias británicas y la creación de la República de los Estados Unidos. En cualquier caso, la versión era de gran calidad. Prueba de ello es que Rato españolizaba los lugares geográficos y buena parte de los nombres propios; también respetaba normalmente las letras cursivas del original. Además de los habituales cambios formales y de ocasionales errores de traducción ${ }^{21}$, solo sobresale la voluntad del traductor de suavizar el lenguaje político de la obra. Esto ocurre, por ejemplo, cuando se omite la palabra révolution o esta es traducida como "alteraciones", al igual que criminelles, como "culpables". No obstante, los rasgos que más singularizan la edición de la traducción son dos breves textos bajo la forma de "Advertencia" y de "Prólogo". En ambos se avanzaba la posición favorable del traductor a Byng, subrayando que su lucha era "en favor de la libertad de su patria que amaba tiernamente". A su vez, en el segundo se reconocía abiertamente que el libro era una traducción del francés ${ }^{22} \mathrm{y}$ que ésta había sido realizada por el encargo de una "persona muy amable, y a quien mantengo particular inclinación, veneración y respeto", que, sin embargo, no era desvelada ${ }^{23}$. Cabe pensar que se tratara una autoridad de la Hacienda, lo cual vendría a ratificar la enorme trascendencia de este departamento gubernamental en la diseminación en España de textos sobre Economía Política.

\section{III.- LOS “VICIOS INVETERADOS” DEL SISTEMA POLÍTICO BRITÁNICO}

El hilo conductor que articula toda la narración de Byng es su crítica al funcionamiento real del sistema político y económico británico. Junto a ello, se percibe el eco de la anglofobia propia de la secular rivalidad franco-británica. Esta, según sostiene el autor del Testament, poseía raíces muy profundas: "se educa al pueblo inglés en el aborrecimiento de los franceses", odio que se erigía en un pilar del patriotismo británico, hasta el punto de condicionar plenamente su política, no solo la internacional cuanto también la nacional: todo valía cuando se trataba de hacer la guerra a Francia. En esta línea, el conflicto que pasaría a denominarse de los Siete Años, era tratado en la narración de Byng como una agresión de Gran Bretaña contraria al Derecho de gentes y a los tratados internacionales. Su objetivo era convertir en realidad la tradicional ambición de Gran Bretaña de erigirse en una Monarquía universal, con un propósito eminentemente comercial, para "atraer a sí sola todo el comercio" 24 . El autor del Testament politique entendía que dicha pretensión era indeseable, en tanto que, en expresiones que evocan el proyecto pacifista y humanitario de l'Abbé Saint Pierre, Europa era percibida como una suerte de república cuya supervivencia requería paz y harmonía internas. No obstante, la materialización del mencionado propósito era virtualmente imposible. En la "república europea" no había espacio para ominosos proyectos de dominación universal. El equilibrio europeo exigía contenerlos, de ahí que la reacción bélica de Francia se hallara

21 El traductor no solo alteraba la estructura de los párrafos sino que, por ejemplo, traducía convention como "conventículo", chef d'oeuvre, como "golpe pasmoso", o policé, como "ilustrado".

22 Se mencionaba como señuelo la obra de Sébastien-Joseph Ducry, Amusement curieux et divertissant, J. Mossy, Florencia-Marsella, 1766-1770.

23 Testamento politico, op. cit., "Prólogo", sin paginar.

24 Testamento político, op. cit., p. 13. 
plenamente justificada. Además, Gran Bretaña se equivocaba al pensar que la derrotaría únicamente por su mayor poder naval y había cometido, ya desde el inicio mismo de la Guerra, errores estratégicos graves: en vez de confiar su suerte al dominio naval, su "altiva" alianza con Prusia (1756) y la consiguiente gravosa financiación de sus tropas aliadas en el Continente se presentaban como un pesado lastre que podía terminar por inclinar el conflicto bélico del lado francés. En la obra, se apelaba a la futura entente entre Francia y España, que se materializará en 1761, en el tramo final de la Guerra, con la firma del Tercer Pacto de Familia, con el fin de contener, si bien sin ningún éxito, la ambición británica.

El análisis puramente bélico se acompañaba en el Testament politique de una valoración profundamente negativa del sistema político británico. La guerra era un reflejo de la insaciable avidez británica pero también una expresión descarnada de la toxicidad de ese sistema. La envidiada libertad civil y politica británica era más aparente que real. El problema residía en una facción próxima al Rey, denominada reiteradamente "realista", constituida, en términos textuales, como un "partido", que ejercía su poder despótico sobre el Parlamento. La larga y detallada digresión sobre la historia política de Inglaterra relatada en el texto refiere la secular lucha entre el Rey y el Parlamento por el control del sistema político y, más en concreto, pormenoriza las estratagemas del primero para liquidar el margen de actuación de los representantes del pueblo. Mientras las etapas en las que el Rey había dejado que el Parlamento gozara de sus privilegios eran las más dichosas, en el periodo en cuestión todo se halla corrompido, debido a la hegemonía del partido realista, expresión con la que la obra se refiere al poderoso Gabinete gubernamental, con un monarca prácticamente ausente. $\mathrm{Si}$ la acción de los ministros del Rey se hallaba guiada por sus intereses particulares, la de los parlamentarios, cuando actuaban libres de interferencias, se basaba en la sabiduria y la virtud, y pretendía el bien de la patria. Por último, si la hegemonía del Parlamento garantizaba el Estado de Derecho, la del Rey lo arrumbaba. En suma, bien lejos de disfrutar de las libertades civiles y políticas, así como de la división de poderes y del equilibrio entre el Rey y el Parlamento, el pueblo británico aparecía sojuzgado por el poder despótico del llamado "partido realista".

Según se relata en el Testament politique, el mecanismo recurrente por el que el partido realista había logrado sus objetivos era nítido. Si la indeseable y peligrosa aparición de "partidos" era un componente inherente al sistema británico, la estrategia del Rey era fomentar aún más la división, alentando facciones cuya raíz era no sólo política sino también religiosa. La vía era la compra "bajo mano" de las voluntades de los parlamentarios para ponerlas después al servicio del partido realista. En la misma medida en que en Gran Bretaña todos los ciudadanos deseaban formar parte de esa "augusta asamblea" parlamentaria, símbolo de la representación de la nación en cuerpo político, el atractivo de los "honores, dignidades y fortuna" se erigía como un poderoso instrumento para la compra de voluntades ${ }^{25}$. El sistema político inglés agudizaba el deseo de complacencia y de riquezas debido a la facilidad que tenían los ciudadanos en vender sus votos. En el Testament politique se hacía mención implícita a la teoría del clima de Montesquieu, según la cual aquel era la razón

25 Testamento politico, op. cit., p. 178. 
del espíritu melancólico de los ingleses. No obstante, haciendo uso de un tópico omnipresente en la tradición republicana, en el texto emergía con fuerza la ubicua tensión entre la "virtud" y las "riquezas": en la medida en que el amor a estas últimas era un poderoso móvil del interés personal, la virtud no era suficiente para controlar la conducta humana. Todo ello incrementaba la eficiencia del partido realista. Los esfuerzos del Parlamento, con la ayuda del pueblo, no habian tenido otro fin que "el aumento de los privilegios de la nación y la disminución de la autoridad del Rey", en realidad, con muy poco éxito. El problema radicaba en que el Parlamento se habia inclinado una y otra vez ante las ambiciones del partido realista. De esta manera, el Rey había maniatado su margen de maniobra. Los parlamentarios dejaban asi de velar por los intereses comunes al mismo tiempo que el interés de la nación se diferenciaba del propio de los ministros del Rey. Y en la medida en que esta conducta del monarca para convertir el Parlamento en un órgano sobornado era generalizada y persistente, se convertía en un "vicio inveterado". El Testament politique podía dibujar así un régimen alejado de cualquier atisbo de instigador de la libertad: era "prostituido" y "corrupto" debido al sometimiento de los pusilánimes parlamentarios a los intereses de los realistas. El problema es que, ya instalada en la corrupción, Gran Bretaña dificilmente podía regresar a sus "primeros principios de gobierno" a través de las reglas y los mecanismos ordinarios.

Según se relata en el Testament politique, Gran Bretaña estaba llamada a ser, entre todas las naciones europeas, la más libre de "alborotos, facciones y mal gobierno", el gobierno por "excelencia" o, incluso, el modelo de la "política sana"26. Pudo haber un tiempo en el que el Parlamento actuaba con su auténtico sentido republicano de independencia, libertad y virtud, presidido por el bien de la patria. Sin embargo, la dinámica antes descrita, enquistada como una práctica plurisecular y regular, transformaba en supuestas todas esas virtudes. Impedia al Parlamento transformarse en una garantía de elaboración de leyes duraderas y estables, impidiendo que el sistema politico sufriera alteraciones permanentes y careciera de estabilidad y tranquilidad. Por el contrario, su divisa era la de un régimen faccionario y dividido, sometido al omnímodo poder del rey. Gran Bretaña carecía así de las principales virtudes que se reclamaban a cualquier régimen político: en el libro se añoraba la construcción de un sistema "fijo" de politica, basado en un conjunto de leyes "sabias, fijas y duraderas"27, que pudiera transmitir estabilidad al sistema politico. Entre ellas figuraba el establecimiento por ley y por tiempo ilimitado de la convocatoria del Parlamento para evitar que se hallara al albur de los caprichos del Rey.

Todos estos mecanismos descritos explicaban que Gran Bretaña fuera una nación esencialmente bélica. Su historia se escribia como una continua disputa entre el Rey y el Parlamento para frenar la demanda de aquel de subsidios para sostener los conflictos bélicos. La guerra se erigía así en un sistema de gobierno en si mismo. Se transformaba en un mero ejercicio de soberania real, toda vez que el Parlamento carecía de capacidad para frenar la exigencia continuada de

${ }^{26} \mathrm{En}$ estas afirmaciones parecen resonar las ideas de Jean-Bernard Le Blanc ("Préface du traducteur", en Discours politiques de Monsieur Hume traduits de l'anglois, Michel Groell, Dresde, 1755, vol. I, pp. 5-48), traductor francés de Hume y Bolingbroke, quien admitía que Gran Bretaña se había convertido en una "escuela de Politica para otros países de Europa", aunque, de acuerdo con Hume, fuera dificil establecer sus reglas generales.

27 Testamento politico, op. cit., pp. 76 y 182. 
préstamos públicos. En muchos casos, la guerra era una mera argucia de los realistas para abatir al Parlamento. Con ella se pretendía no tanto dominar nuevos territorios extranjeros cuanto destruir la discrepancia interna manteniendo cohesionada la nación en torno al rey: todo valía cuando se trataba de abatir a Francia. Mantener exhaustas las finanzas públicas se convertía así en un poderoso instrumento de dominación. Incluso en las épocas de paz era necesario recurrir al endeudamiento en la previsión de las futuras guerras.

Debido a todo ello el Parlamento era incapaz de cumplir con sus obligaciones constitucionales: no ejercia su labor de control del monarca y de transparencia pública. Una de las consecuencias más perniciosas de ello es que carecía de instrumentos para sujetar el nivel de endeudamiento: la tendencia al aumento de este era inherente al sistema británico. No obstante, el Testament politique se hacía eco del debate sobre la deuda pública omnipresente en el siglo XVIII europeo ${ }^{28}$ - más en concreto, de las conocidas posiciones de Hume ${ }^{29}$ - y que conoció una notable intensificación precisamente a raíz de los devastadores efectos de la Guerra de los Siete Años sobre el sistema financiero europeo ${ }^{30}$. En la obra se realizaba una auténtica desestimación de la política de recurso continuo al crédito público; más aún cuando, como era el caso británico, su motivación era esencialmente bélica. Estaba dirigida a financiar tanto el armamento como a las potencias extranjeras aliadas. El resultado era que Gran Bretaña se hallaba cercada por una deuda pública "espantosa", "infinitamente superior a nuestro numerario"; debería conquistar el reino de Francia para salir del "abismo"31. Así, el horizonte del défaut, ya planteado por Bolingbroke, autor bien conocido por esa fechas en Francia y en España ${ }^{32}$, no era impensable: si la tendencia no se invertía, "será preciso al fin quebrar". Estas reflexiones se diseminaban en España en un momento realmente oportuno. No solo porque en los años ochenta los problemas de endeudamiento de la Hacienda española emprenderán una senda de empeoramiento irrecuperable, sino debido a que diversas traducciones previas, en particular las realizadas en los años setenta por el servidor de la Hacienda real Domingo de Marcoleta de los escritos de

28 Una visión panorámica en Michael Sonenscher, Before the deluge: Public debt, inequality, and the intelectual origins of the French Revolution, Princeton University Press, Princeton, NJ, 2007.

29 David Hume, Discours politiques, traduits de l'anglois de Monsieur Hume, Michael Groell, Dresde [París], 1755, discurso VIII. Acerca de la amplia recepción de sus Political Discourses en la Francia de los años cincuenta, incluida la versión de Jean-Bernard Le Blanc, aquí consultada, vid. Loïc Charles, "French 'New Politics' and the Dissemination of David Hume's Political Discourses on the Continent, 1750-1770", en C. Wennerlind and M. Schabas (edit.), David Hume's Political Economy, Routledge, Londres-Nueva York, 2008, pp. 181-202. La traducción española de esta obra de Hume vio la luz en 1789.

30 El juicio del sagaz Adam Smith en La riqueza de las naciones (1776; Fondo de Cultura Económica, México, 1958, pp. 389-390) puede ser suficiente para ratificar que Gran Bretaña y Francia financiaron la guerra recurriendo esencialmente al crédito público.

31 Testamento politico, op. cit., p. 208.

32 Henry St John Bolingbroke, Vizconde de, “Réflexions politiques sur l’État présent de l'Angleterre, principalement à l'égard de ses taxes et de ses dettes, et sur leurs conséquences, traduites de l'anglois de Mylord Bolingbroke", en Discours politiques de Monsieur Hume traduits de l'anglois. Nouvelle édition par Monsieur L'Abbé Le Blanc, Michel Groell, Dresde, 1755, vol. I, pp. 221-286. Esta traducción francesa circuló en España desde comienzo de los años sesenta acompañando la versión francesa de los Political Discourses de Hume. 
Greenville y de Accarias de Serionne, ya habian entrelazado estrechamente el nivel desbordado de deuda pública con la anglogobia33.

En cualquier caso, todo era una simple consecuencia de un régimen esencialmente corrupto: bajo el manto de las leyes, se hicieron acreedores del Estado una multitud de particulares con voto en las deliberaciones parlamentarias. También se hallaban implicadas en ello las compañias de comercio, deseosas de ofrecer préstamos a cambio de privilegios. Todo esto era sin duda un problema en una Monarquía, donde los ministros podían ocultar a la nación el empleo de los fondos públicos; pero no debería serlo en Gran Bretaña, donde el Parlamento poseía supuestamente esa potestad de control. El problema radicaba en que este se habia prestado cobardemente a los planes ambiciosos de los realistas. Todo surgía por tanto de una "mala inteligencia doméstica", cuyo origen se hallaba en una Constitución "viciosa". Solo algún remedio violento podia hacer que la "virtud" cobrara su superioridad: una "revolución" habria de libertar al pueblo británico de su esclavitud 34 .

De esta manera, en suma, el análisis del sistema político británico expuesto en el Testament politique era realmente devastador. Venía a nutrir una corriente anglófoba de la Ilustración española que había adquirido su nueva carta de naturaleza precisamente con ocasión de la Guerra de los Siete Años y el enorme éxito que esta había reportado a Gran Bretaña, especialmente en la esfera imperial. Las entregas periodísticas del prolífico Mariano Nifo o las traducciones españolas del autor francés afincado en Austria Accarias de Serionne eran dos ejemplos muy significativos de que el cauce sobre el cual se abonará la anglofobia del Testament politique se hallaba ya firmemente cimentado ${ }^{35}$. En cualquier caso, en el momento preciso en que en España comenzaba a eclosionar el debate constitucional, es indiscutible que el libro pretendía incidir en la formación de la "opinión" en una línea marcadamente oficial" ${ }^{36}$. Así lo muestra

33 Vid., respectivamente, de Jesús Astigarraga, "La finalidad política de las traducciones económicas: George Grenville en la Ilustración española”, Historia y Politica, n 27/1, 2012, pp. 169-201.y "Jesús Astigarraga, "Spain and the economic work of Jacques Accarias de Serionne", en S. L. Kaplan y S. A. Reinert (edit.), The Economic Turn. Recasting Political Economy in Eighteenth-Century Europe, Anthem Press, Londres, 2018, pp. 607-633”.

34 Testamento político, op. cit., pp. 197-198.

35 Debe recordarse, del primero, en particular, que en 1779 realizó una reedición conjunta de sus cabeceras periodísticas, profundamente antibritánicas, la Estafeta de Londres (1762) y el Correo General de Europa (1763), elaboradas en plena Guerra de los Siete Años: Francisco Mariano Nifo, Estafeta de Londres, y extracto del Correo General de Europa, Miguel Escribano, Madrid, 1779, 2 vol. y Jesús Astigarraga, "Prensa económica de la Ilustración española (17581792)", Studia Histórica- Historia Moderna, n 40-2, 2018, pp. 199-232.E1 segundo fue autor de La richesse de l'Angleterre (1771), traducido al español tres años después y uno de los textos más críticos acerca de Gran Bretaña de todo el siglo XVIII español: Jacques Accarias de Serionne, La riqueza de Inglaterra, Madrid, 1774. Una interpretación de esta segunda obra se halla en J. Astigarraga, "Spain and the economic work", op. cit.

36 Acerca de la relación entre la configuración de la "opinión" y la literatura económico-política, vid. Javier Usoz, "La "nueva política" ilustrada y la esfera pública: las introducciones a la economía en el siglo XVIII español", Revista de Estudios Politicos, n 153, 2011, pp. 11-46; "Los prólogos económicos y la esfera pública ilustrada en España", en J. Astigarraga y J. Usoz (edit.), L'Économie politique et la sphère publique dans le débat des Lumières, Casa de Velázquez, Madrid, 2013, pp. 83-102; "Political economy and the creation of the public sphere during the Spanish Enlightenment", en J. Astigarraga (edit.), Voltaire Foundation, Oxford, 2015, pp. 105-128. 
que respondiera a la demanda de una autoridad desconocida. Para mayor abundamiento, esta misma estrategia publicística se repetirá pocos años después, justo en el momento en que había finalizado la Guerra anglo-española de 1779-1783. En este último año José Covarrubias, plumista entonces al servicio del Secretario de Estado Floridablanca, daba a la luz un relato histórico, a él dedicado, sobre el origen de ese conflicto bélico: las desavenencias de las colonias americanas con su metrópoli. Tras describir sucintamente el gobierno británico y la historia de esas colonias, Covarrubias justificaba su obra con el fin de contribuir a la formación de una adecuada "opinión pública", en este caso contra el opositor británico, a quien acusaba de ser el responsable de la pérdida de sus enclaves coloniales. La "opinión pública" era presentada ya por Covarrubias abiertamente con la categoria de "la regla fija del gobierno". En sus palabras, "nunca debe éste chocarla sin razones públicas, ni contradecirla, sin haberla antes desengañado y persuadido, y según ella, se deben modificar todas las formas de gobierno". Ello era debido a que "la reclamación del público es constantemente el grito de la opinión; y la opinión es la regla general de todo gobierno [...] y así los gobiernos se mejoran y perfeccionan al paso que las opiniones" 37 .

\section{IV.- EN DEFENSA DEL LIBRE COMERCIO}

Los mecanismos de corrupción naturalizados con el sistema político británico arrojaban también su sombra sobre el sistema económico. En esta vertiente el problema principal lo suscitaba la ausencia de libertad de comercio. Por sus características geográficas y naturales - en particular, debido a su condición insular- Gran Bretaña debía estructurar su economía productiva en torno al principio de libertad de comerciar. Sin embargo, los mecanismos de compra de voluntades en la arena parlamentaria, a través del otorgamiento de subsidios y privilegios, habian estrechado el comercio hasta constreñirlo en unas pocas manos. En el Testament politique se exponía una auténtica diatriba contra la economía de los privilegios comerciales. En particular, se apuntaba a las cinco compañias de comercio privilegiadas británicas, comenzando por la Compañía de Indias orientales. Estas reflejaban, mejor que cualquier otra manifestación similar, todos los efectos devastadores de un sistema comercial restringido y mediado por el poder político.

Todo era en esencia una simple derivación de los principios del Derecho Natural. La máxima de un Estado bien gobernado sería no excluir a ninguna persona del comercio que era propio de toda nación. Las consecuencias que solian atribuirse al ejercicio del comercio por medio de compañias privilegiadas

\footnotetext{
37 José Covarrubias, Memorias históricas de la última guerra con la Gran Bretaña, Andrés Ramírez, Madrid, 1783, pp. XLII-XLIII. La obra quedó inacabada. Este primer volumen estaba dedicado a los años 1774 y 1775. Todo ello no era sino un reflejo más de la poderosa penetración en España de las ideas político-económicas de Necker; vid. Jesús Astigarraga, "La traduction au service de la Politique. Le succès de Jacques Necker dans les Lumières espagnoles", Annales Historiques de la Révolution Française, no 364, 2011, pp. 3-27.
} 
- mala gestión, administración onerosa o precios elevados- eran menos graves que sus efectos sobre el conjunto del sistema socioeconómico en las esferas de la eficiencia económica y de la moralidad del sistema político: quien incumplía esos principios, como era el caso de las compañias privilegiadas, atentaba sencillamente contra las leyes naturales; por ello, su daño era doblemente dañino. Se manifestaba incluso en los privilegios otorgados por tiempo limitado: era difícil destruir un monopolio después de haberlo creado. Detrás de estas ideas se hallaban las primeras críticas sustanciales al sistema de privilegios comerciales planteadas en la Francia de los años cincuenta. Y dado que en el texto no existen ecos de resonancias fisiócratas, todo apunta al influjo del influyente grupo de Gournay, siguiendo la senda del pensamiento británico abierta por Hume; además de el propio Gournay, a autores como Clicquot de Blervache, Turgot o Morellet ${ }^{38}$.

El punto de partida de todo ello era la tesis iusnaturalista de la sociabilidad del comercio: los ciudadanos ejercian este porque obtenian ventajas mutuas del mismo. No obstante, ese cambio mutuamente beneficioso generaba también efectos positivos sobre el conjunto de la comunidad politica ${ }^{39}$. El comercio ataba por interés a los particulares que componian la sociedad y se erigía en una actividad insoslayable para mantener vivo en ella el "espiritu republicano". En el Testament politique afloraba la importancia del comercio para mantener "a los que lo ejercitan en el espíritu republicano"40. Ahora bien, ello sucedia siempre y cuando el comercio fuera libre. Dos vías apuntalaban esta ligazón entre comercio libre y "espíritu republicano"41. En primer lugar, la libertad de comercio poseía efectos redistributivos; era la mejor garantía para alcanzar un sistema socioeconómico más igualitario y contribuir así a extender el bien de la comunidad. Esto se debía, entre otros motivos, a que, en las antípodas de lo que provocaban las compañias privilegiadas, garantizaba la abundancia y baratura de bienes. La igual distribución de fortunas mantenía la unión entre los ciudadanos y los hacía concurrir al bien del Estado. En segundo lugar, la libertad de comercio excitaba la emulación entre los ciudadanos; constituía el mejor mecanismo para repartir en proporción al talento el trabajo de quienes participaban en el comercio. Esto último era también un principio derivado del iusnaturalismo: era natural que cada ciudadano comerciase libremente e hiciera valer la industria y talentos que debía a la providencia.

Todo ello era especialmente evidente cuando aparecía un nuevo ramo de comercio. Este era debido a un "talento superior", que le otorgaba a quien lo poseía cierta superioridad sobre el resto de sus conciudadanos. Ahora bien, dado

38 Sobre la politica de Gournay y su círculo combativa de los privilegios comerciales, pueden verse, entre otros, Simone Meyssonnier, La balance et l'horloge. La genèse de la pensée libérale en France au XVIIIe siècle, Éditions de la Passion, París, 1989, y Arnault Skornicki, L'économiste, la cour et la patrie, CNRS, París, 2011.

39 Testamento politico, pp. 227-228. Sobre el desarrollo de las tesis de la sociabilidad de comercio a partir de Puffendorf, vid. Catherine Larrère, L'invention de l'Économie au XVIIIe siècle. Du droit naturel à la physiocratie, PUF, París, 1992, cap. 1, e Istvan Hont, Jealousy of Trade, Cambridge University Press, Cambridge-Massachusets-Londres, 2005, pp. 159-184.

40 Testamento politico, op. cit., p. 216.

41 Testamento politico, op. cit., p. 216. 
que no se podía excluir a una nación de las ventajas de los nuevos descubrimientos, todos los conciudadanos se beneficiaban de ellas a medida que se iban diseminando. En la sociedad comercial, el deseo de riquezas era más intenso que el de honores, por ello resultaba particularmente trascendente el ejercicio de una actividad como el comercio que, bien regulado, permitía la búsqueda del interés individual sin dañar al común. En cualquier caso, esta dinámica solo se podía materializar en un régimen de libre comercio. Este garantizaba la percepción de beneficios "normales", en vez de "extraordinarios", como era el caso de los monopolios, y ello apuntalaba las condiciones de igualdad y de beneficio para la colectividad:

"cuando el comercio es libre, el mercader solo consulta su interés particular, vive frugalmente $\mathrm{y}$ se contenta con una mediana ganancia [...] la abundancia abarata las mercancías y mayor número de ciudadanos halla su subsistencia en la multiplicación de negocios corrientes que un comercio libre mantiene indispensablemente en un Estado" 42.

Mientras tanto, el sistema de compañias privilegiadas de comercio se presentaba como el principal ejemplo contrario a estos principios -en el texto también se criticaban los privilegios concedidos a las manufacturas cercanas a la capital o los permisos exclusivos sobre la importación-. Esas compañias, lejos de contribuir a la igualdad, la impedian, al favorecer una "desproporción exorbitante en el repartimiento de bienes"; lejos de favorecer las virtudes de la frugalidad y la contención, obligaban a mantener activo un consumo suntuario como única vía para garantizar la distribución de esos caudales acumulados en pocas manos; por fin, lejos de instigar la emergencia de ciudadanos libres movidos por su propio interés, envilecian el sistema social y obligaban "a hacerse esclavos los que deberian ser iguales". Así pues, eran más propias de los tiempos de la "barbarie" y de la "ignorancia"; solo tenian lugar en "un país donde el pueblo sea esclavo y el monarca despótico"43. No eran sino la expresión de una forma de abuso que atentaba contra los "derechos del hombre". El mecanismo mediante el cual se ponían al servicio del partido realista era muy simple: intercambio de privilegios por apoyo financiero. Llegado el momento, eran las principales acreedoras del Estado, con cobros de intereses usurarios, que perjudicaban gravemente al bien común.

El ejemplo británico revelaba precisamente cómo el sistema de compañías apuntalaba un régimen despótico. Estas habian acabado por transformarse en una especie de "república dentro de la república", incluso con capacidad para sostener sus propios ejércitos. Al mismo tiempo, generaban enormes desigualdades sociales, incluido el aumento desmedido del lujo, hasta el punto de que solo debian adoptarse en un "país donde el pueblo sea esclavo y el monarca despótico"44. Controlar su actividad y ganar su adhesión a la causa realista resultaba tan simple como comprar su voluntad en la escena parlamentaria. En cambio, todo ello no resultaba tan sencillo en un sistema de libre comercio en el que operaba una gran multitud de compañias y

\footnotetext{
42 Testamento politico, op. cit., p. 231.

43 Testamento politico, op. cit., p. 229.

44 Testamento político, op. cit., p. 229.
} 
comerciantes. De esta manera, ese sistema se podía presentar realmente como el único posible que podría llegar a garantizar un régimen de sustrato republicano.

En suma, la potencia británica no podía alcanzar su verdadera felicidad más que con la mayor extensión de la libertad de comercio. Todas estas ideas estaban destinadas a tener una buena acogida en la Ilustración española. No sólo venían a reforzar la corriente contraria a los privilegios comerciales que venía extendiendo su influencia desde los años sesenta, sino que arribaban al país poco después de que en 1778 hubiera sido decretado el Reglamento del comercio libre con las colonias, profundización del previo, decretado en 1765, y a través del cual el gobierno ilustrado pretendia abandonar definitivamente en el seno del sistema imperial español el sistema de compañias privilegiadas y dejar definitivamente ese comercio en manos del tráfico privado ${ }^{45}$.

\section{V.- A MODO DE CONCLUSIONES}

A pesar de haber sido virtualmente olvidado, el Testamento politico del almirante Bing, considerado en conjunto con la obra original en francés de la que es traducción, constituye una pieza de notable importancia en la doble vertiente del conocimiento sobre el funcionamiento real de la política británica del siglo XVIII, por un lado, y de la reconstrucción de las fuentes intelectuales del siglo XVIII español, por otro, más en particular, en las relativas a las de la literatura económico-política.

Por lo que se refiere a la primera de las vertientes mencionadas, más ligada al momento de su publicación en 1759, la obra de autoría desconocida y ficticiamente atribuida al almirante Byng, además de estar asociada a la propaganda opuesta a la declaración de guerra británica contra los intereses de Francia, pertenece a la tradición europea más mordaz de escritos de crítica política, cuyo origen a finales del siglo XVII es fundamentalmente británico. En este sentido, la anglofobia del texto puede ser percibida como una oposición radical, no tanto a un pueblo o a una nación, cuanto a una forma de ejercer el poder que consiste en la práctica en degradar las instituciones y el sistema politico definido por la monarquía parlamentaria instaurada en Inglaterra en 1688, en favor de los intereses de una camarilla, personificada por el Gabinete, que, a su vez, representa unos concretos intereses socioeconómicos, muy próximos a los de las grandes compañias comerciales privilegiadas. Estas se han constituido en un Estado dentro de otro Estado y compran las voluntades parlamentarias del partido "whig", dominante durante gran parte del siglo XVIII, hasta el punto de lograr, como se denuncia en este caso concreto, que se declare una guerra cuyos ingentes costes, en definitiva, va a soportar el pueblo en forma de impuestos y deuda pública.

Esta critica al funcionamiento efectivo y tergiversador de las instituciones políticas británicas, que contiene una visión de realpolitik, sintoniza con los enfoques sociopolíticos pragmáticos de Montesquieu y Hume, a la vez que sostiene planteamientos iusnaturalistas y la virtud del republicanismo clásico. A mediados del siglo XVIII, este conjunto de principios se halló más cercano a la causa entonces opositora del sector "tory" de la política británica, sostenida por la

45 Stanley J. Stein y Barbara H. Stein, Apogee of Empire: Spain and New Spain in the Age of Charles III, 1759-1789, Johns Hopkins University Press, Baltimore, 2003, pp. 83-95. 
pequeña propiedad rural, los artesanos y el comercio tradicional. En ese momento, dicha causa, aunque no lo pudiera manifestar abiertamente para no ser tildada de antipatriota, discutiria la oportunidad de emprender una onerosa guerra contra Francia.

Por lo que se refiere a la traducción española, editada en 1780, también poseía una finalidad esencialmente política, con derivada económica, si bien, lógicamente, en un contexto diferente. En suma, a través de ella se pretendia trasplantar la versión original del texto, publicado en 1759, en plena Guerra anglo-francesa de los Siete Años, al nuevo escenario bélico anglo-español de 1779-1783. Más allá de contribuir al debate constitucional entonces en ciernes, la finalidad principal de la misma era moldear el espiritu patriótico de la opinión pública española frente al opositor británico. Su publicación reflejaba el interés de los traductores españoles de utilizar nuevos estilos narrativos con el fin de aproximar las novedosas ideas económico-politicas al público. En este caso, las dos ideas que vertebraban el texto original encajaban perfectamente en las diversas líneas centrales de la Ilustración española, así como en el contexto preciso en el que la traducción fue publicada. Si la anglofobia era una motivación política lógica en el inicio del nuevo conflicto bélico con Gran Bretaña, la diatriba contraria a las compañias privilegiadas y en defensa del libre comercio enlazaba con el programa económico liberalizador característico de la segunda mitad del siglo XVIII español y cobraba una notoriedad aún superior si tenemos presente que la traducción vio la luz poco después de decretado en 1778 el Reglamento del comercio libre con las colonias. Y esa misma afinidad con la realidad española puede afirmarse respecto a las fuentes que inspiraban el texto original. Mientras las de naturaleza política entrelazaban estrechamente ideas arraigadas en las tradiciones del Derecho Natural y el republicanismo, su vertiente más estrictamente económica se hacía eco del reformismo liberalizador instigado en los años cincuenta por el grupo de Gournay, una de las fuentes más influyentes del pensamiento económico de la Ilustración española.

\section{BIBLIOGRAFÍA}

Jacques Accarias de Serionne, La riqueza de Inglaterra: que explica las causas del origen y progresos de la industria, el comercio y la marina de la Gran Bretaña, los motivos de su decadencia y el estado de sus actuales fuerzas y recursos, Miguel Escribano, Madrid, 1774.

Francisco Aguilar Piñal, Bibliografía de autores españoles del siglo XVIII, CSIC, Madrid, 1981-2001, 10 vol.

Anónimo, Charles premier, roi d'Angleterre, condamné à mort par la nation angloise, et Bing, amiral anglois, fusillé par ordre de la même nation. Entretiens de leurs ombres aux Champs Elisées, J. Neaulne, Ámsterdam, 1757.

Anónimo, Testament politique de l'amiral Byng, traduit de l'anglois, s. e., Portsmouth [Paris], 1959.

Anónimo, Bing au peuple anglois, [París], 1760. 
Anónimo, Testamento politico del almirante Bing en el que se manifiestan las máximas del partido realista para sojuzgar al pueblo inglés y quitarle la libertad que se ha adquirido; y asi mismo la senda que éste debe seguir para conservarla. Traducido del francés por Don Antonio Rato, Oficial primero de la Tesoreria del Ejército y Reino de Valencia, José y Tomás de Orga, Valencia, 1780.

Jesús Astigarraga, "La traduction au service de la Politique. Le succès de Jacques Necker dans les Lumières espagnoles", Annales Historiques de la Révolution Française, n ${ }^{\circ} 364,2011$, pp. 3-27.

Javier Usoz, "La "nueva politica" ilustrada y la esfera pública: las introducciones a la economía en el siglo XVIII español", Revista de Estudios Políticos, $\mathrm{n}^{\circ}$ 153, 2011, pp. 11-46. Incluirlo en orden correcto en la bibliografia (vid infra).

Javier Usoz, "Los prólogos económicos y la esfera pública ilustrada en España", en J. Astigarraga y J. Usoz (edit.), L'Économie politique et la sphère publique dans le débat des Lumières, Casa de Velázquez, Madrid, 2013, pp. 83-102.

Javier Usoz, "Political economy and the creation of the public sphere during the Spanish Enlightenment", en J. Astigarraga (edit.), Voltaire Foundation, Oxford, 2015, pp. 105-128.

Jesús Astigarraga, "La finalidad politica de las traducciones económicas: George Grenville en la Ilustración española", Historia y Politica, n ${ }^{\circ}$ 27/1, 2012, pp. 169201.

Jesús Astigarraga, "Literatura económica de combate. La traducción española del Chinki de Coyer", en J. A. Pardos et. al. (edit.), Historia en Fragmentos. Estudios en homenaje a Pablo Fernández Albaladejo, Madrid, Universidad Autónoma de Madrid, 2017, pp. 691-700.

Jesús Astigarraga, "Prensa económica de la Ilustración española (1758-1792)", Studia Histórica- Historia Moderna, n 40-2, 2018, pp. 199-232.

Jesús Astigarraga, "Spain and the economic work of Jacques Accarias de Serionne", en S. L. Kaplan y S. A. Reinert (edit.), The Economic Turn. Recasting Political Economy in Eighteenth-Century Europe, Anthem Press, Londres, 2018, pp. 607-633".

Henry St John Bolingbroke, Vizconde de, "Réflexions politiques sur l'État présent de l'Angleterre, principalement à l'égard de ses taxes et de ses dettes, et sur leurs conséquences, traduites de l'anglois de Mylord Bolingbroke", en Discours politiques de Monsieur Hume traduits de l'anglois. Nouvelle édition par Monsieur L'Abbé Le Blanc, Michel Groell, Dresde, 1755, vol. I, pp. 221-286.

José Covarrubias, Memorias históricas de la última guerra con la Gran Bretaña, Andrés Ramírez, Madrid, 1783.

Loïc Charles, "French 'New Politics' and the Dissemination of David Hume's Political Discourses on the Continent, 1750-1770", en C. Wennerlind and M. Schabas 
(edit.), David Hume's Political Economy, Routledge, Londres-Nueva York, 2008, pp. 181-202.

Sébastien-Joseph Ducry, Amusement curieux et divertissant, J. Mossy, FlorenciaMarsella, 1766-1770.

Edmond Dziembowski, Un nouveau patriotisme français, 1750-1770, Voltaire Foundation, Oxford, 1998.

Edme-Jacques Genet, Mémoire pour les ministres d'Angleterre, contre l'amiral Byng et contre l'auteur du Peuple instruit. Ouvrage traduit de l'anglois, s. e., s. 1., 1757.

Ange Goudar, Les intérêts de la France mal entendus, Ámsterdam [Avignon], 1756, 3 vol.

Joséphine Grieder, Anglomania in France 1740-1789, Droz, Ginebra, 1985.

Jean-Claude Hauc, Ange Goudar. Un aventurier des Lumières, Honoré Champion, París, 2004.

Istvan Hont, Jealousy of Trade, Cambridge University Press, CambridgeMassachusets-Londres, 2005.

David Hume, Discours politiques, traduits de l'anglois de Monsieur Hume, Michael Groell, Dresde [París], 1755.

Samuel Johnson, Escritos politicos (ed. Donald J. Green), Katz, Buenos Aires, 2009.

Journal encyclopédique, abril 1759.

Catherine Larrère, L'invention de l'Économie au XVIIIe siècle. Du droit naturel à la physiocratie, PUF, París, 1992.

Jean-Bernard Le Blanc, "Préface du traducteur", en Discours politiques de Monsieur Hume traduits de l'anglois, Michel Groell, Dresde, 1755, vol. I, pp. 5-48.

José Antonio Maravall, "Las tendencias de reforma politica en el siglo XVIII español", en Estudios de la historia del pensamiento español (siglo XVIII), Mondadori, Madrid, 1991, pp. 61-81.

Mercurio Histórico y Politico, agosto 1778.

Simone Meyssonnier, La balance et l'horloge. La genèse de la pensée libérale en France au XVIIIe siècle, Éditions de la Passion, París, 1989.

Francisco Mariano Nifo, Estafeta de Londres, y extracto del Correo General de Europa, Miguel Escribano, Madrid, 1779, 2 vol. 
André-Michel Rousseau, "L'Angleterre et Voltaire (1718-1789)", en Studies in Voltaire and the Eighteenth Century (vol. 145), Voltaire Foundation y The Taylor Institution, Oxford, 1976.

Adam Smith (1958), La riqueza de las naciones (1776), Fondo de Cultura Económica, México, 1958.

Arnault Skornicki, L’économiste, la cour et la patrie, CNRS, París, 2011.

Michael Sonenscher, Before the deluge: Public debt, inequality, and the intelectual origins of the French Revolution, Princeton University Press, Princeton, NJ, 2007.

Amstrong Starkey, "To encourage the others': the philosophes and the War", en M. H. Danley y P. J. Speelman (edit.), The Seven Years' War. Global Views, Brill, Leiden-Boston, 2012.

Stanley J. Stein y Barbara H. Stein, Apogee of Empire: Spain and New Spain in the Age of Charles III, 1759-1789, Johns Hopkins University Press, Baltimore, 2003.

Joaquín Varela Suanzes-Carpegna, "El constitucionalismo británico entre dos constituciones: 1688-1789”, Fundamentos. Cuadernos monográficos de Teoría del Estado, Derecho público e Historia constitucional, $\mathrm{n}^{\circ}$ 2, 2000, pp. 8-59. Disponible en http:/ / www.jgpa.es/recursos/descargas / 170662463_1532011203623pdf.

Joaquín Varela Suanzes-Carpegna, "El debate constitucional británico en la primera mitad del siglo XVIII (Bolingbroke versus Walpole)", Revista de Estudios Políticos, no 107, 2000, pp. 9-32.

Voltaire, Arouet, F.-M., Candide, ou l'optimisme (1759), Genève, 1761.

Voltaire, Arouet, F.-M., Oeuvres complètes de Voltaire (vol. LXVI). Correspondance Général (vol. V), Badouin Frères, París, 1828.

Chris Ware, Admiral Byng: his rise and execution, Pen and Sword Maritime, Barnsley, 2009.

Fecha de envio / Submission date: 23/10/2018

Fecha de aceptación /Acceptance date: 15/12/2018 